\title{
Evaluation of the Manchester Triage System quality indicator: service time
}

\section{Ana Paula Santos de Jesus ${ }^{a}$ Ruth Ester Assayag Batista ${ }^{\mathrm{b}}$ Cassia Regina Vancini Campanharo ${ }^{b}$ Maria Carolina Barbosa Teixeira Lopes ${ }^{b}$ Meiry Fernanda Pinto Okuno ${ }^{b}$}

\section{How to cite this article:} Jesus APS, Batista REA, Campanharo CRV Lopes MCBT, Okuno MFP. Evaluation of the Manchester Triage System quality indicator: service time. Rev Gaúcha Enferm. 2021:42:e20200371. doi: https://doi. org/10.1590/1983-1447.2021.20200371
Universidade Federal do Recôncavo da Bahia (UFRB), Centro de Ciências da Saúde. Santo Antônio de Jesus, Bahia, Brasil.

' Universidade Federal de São Paulo (UNIFESP), Escola Paulista de Enfermagem. São Paulo, São Paulo, Brasil.

\section{ABSTRACT}

Objective: to verify the conformity of the time interval between the end of the risk classification and the beginning of medical care with that recommended by the Manchester protocol and to relate the times of care and the risk categories with the outcome.

Method: Cross-sectional, retrospective, and analytical study. The t test, the analysis of variance and the generalized linear model were used.

Results: The average time for medical care in the red and orange categories was 3 and 39.5 minutes, respectively. Death outcome was associated with the red category, with an average time to start the classification of 5.5 minutes and an average length of stay of 2.3 hours.

Conclusion: The waiting time for medical care in the high priority categories was longer than recommended, which suggests the need to continuously monitor the system. Shorter waiting times for classification and permanence were related to the red category and the outcome of death.

Keywords: Triage. Emergency medical services. Length of stay. Crowding. Emergency nursing. Protocols.

\section{RESUM0}

Objetivo: Verificar a conformidade do intervalo de tempo entre o término da classificação de risco e o início do atendimento médico com o recomendado pelo protocolo de Manchester e relacionar os tempos de atendimento e as categorias de risco com o desfecho. Método: Estudo transversal, retrospectivo e analítico. Foram utilizados o teste t, a análise de variância e o modelo linear generalizado. Resultados: 0 tempo médio para atendimento médico nas categorias vermelha e laranja foi de 3 e 39,5 minutos, respectivamente. Desfecho óbito associou-se à categoria vermelha, com tempo médio para início da classificação de 5,5 minutos e tempo médio de permanência de 2,3 horas.

Conclusão: 0 tempo de espera para atendimento médico nas categorias de alta prioridade foi maior que recomendado, o que sugere a necessidade de monitorar continuamente o sistema. Menores tempos de espera para a classificação e de permanência relacionaramse à categoria vermelha e ao desfecho óbito.

Palavras-chave: Triagem. Serviços médicos de emergência. Tempo de internação. Aglomeração. Enfermagem em emergência. Protocolos.

\section{RESUMEN}

Objetivo: Verificar el cumplimiento del intervalo de tiempo entre el final de la clasificación de riesgo y el inicio de la atención médica con el recomendado por el protocolo de Manchester y relacionar los tiempos de atención y las categorías de riesgo con el resultado. Método: Estudio transversal, retrospectivo y analítico. Se utilizó la prueba t, el análisis de varianza y el modelo lineal generalizado. Resultados: El tiempo promedio de atención médica en las categorías rojo y naranja fue de 3 y 39,5 minutos, respectivamente. El resultado de la muerte se asoció con la categoría roja, con un tiempo promedio para iniciar la clasificación de 5,5 minutos y una estancia promedio de 2,3 horas.

Conclusión: El tiempo de espera para la atención médica en las categorías de alta prioridad fue mayor al recomendado, lo que sugiere la necesidad de monitorear continuamente el sistema. Los tiempos de espera más cortos para la clasificación y la permanencia se relacionaron con la categoría roja y el resultado de la muerte.

Palabras clave: Triaje. Servicios médicos de urgencia. Tiempo de internación. Aglomeración. Enfermería de urgencia. Protocolos. 


\section{INTRODUCTION}

The organization of care for urgencies and emergencies has been one of the challenges faced by health managers ${ }^{(1)}$. In the national and international contexts, there is an excessive demand from patients who seek care in emergency services $(E S)$, which can influence the quality of care and their safety ${ }^{(2)}$.

In ES, especially in large Brazilian public hospitals, the worsening situation of overcrowding has caused barriers to the flow of care and, consequently, increased waiting time and length of stay in the service, whether due to the high number of non-urgent patients who have difficulty access to outpatient consultations, or by the lack of inpatient beds and intensive care for transfers of stabilized and critically ill patients, respectively ${ }^{(3)}$.

However, there is an advance. Institutional managers are looking for technologies that can help to minimize the effect of overcrowding in the ES when looking at clinical risk management ${ }^{(4)}$. In the national and international scenarios, different triage systems were implemented to quickly identify critically ill individuals upon arrival at the ES and allocate the right patient, in the right place and within the ideal time frame ${ }^{(5)}$.

The Manchester Triage System (MTS) gained prominence as an effective risk classification system (RC) in the national scenario, and clinical priority can be used as an indicator of quality in the ES (1). The MTS is an auditable tool that uses five priority levels and determines the patient's clinical risk combined with the waiting time until the first medical evaluation $^{(1,4)}$. In the SE, patients are submitted to RC and categorized by the MTS, described by colors that indicate the following maximum response times: red color for immediate care; orange $\leq 10$ minutes; yellow $\leq 60$ minutes; green $\leq 120$ minutes and blue $\leq 240$ minutes. The white color is intended for patients referred for procedures, complementary exams or evaluation by specialists ${ }^{(1)}$.

The implementation of the MTS alone does not ensure the optimal functioning of the ES, being necessary to monitor the results, in order to implement improvements in management $t^{(1,6)}$. The process must be audited, including measuring quality indicators, such as average service times ${ }^{(1)}$. The care within the estimated time at each risk level is a decisive factor for patient safety ${ }^{(7)}$. In addition, the waiting time is one of the main reasons for dissatisfaction among users in the $\mathrm{ES}^{(2,8)}$. Thus, quality indicators are essential tools for the management of good health practices, as they can be useful to assess the care provided and characterize the patient's epidemiological profile ${ }^{(9)}$.
At the national level, few studies with the MTS ${ }^{(6-7,10)}$ analyzed the different times of care in hospital ES of the Unified Health System (Sistema Único de Saúde - SUS). However, the measure of length of stay is an indicator of the quality of care that has been investigated ${ }^{(11-14)}$, in addition to being considered a fundamental element for coping with overcrowding in hospitals ${ }^{(4)}$.

Considering the need to assess the RC in the ES after the implementation of the MTS, it is highlighted the importance of comparing the institutional performance with the time recommended by the MTS for monitoring the quality of care and planning actions that contribute to greater effectiveness and efficiency of the care provided. In this sense, the following hypotheses were raised: there is no difference between the waiting time for medical care and the maximum response time for the RC categories indicated in the MTS, and there is no relationship between the service times, $\mathrm{RC}$ categories and the outcomes.

The study aimed to verify the conformity of the time interval between the end of the risk classification and the beginning of medical care with what is recommended by the Manchester protocol and to relate the times of care and the risk categories with the outcome.

\section{METHOD}

Cross-sectional, retrospective, and analytical study carried out in the adult ES of the largest public hospital in Bahia. The service in this hospital is exclusively for SUS users, by spontaneous demand and referenced in the city of Salvador (BA) and other municipalities in Bahia. The MTS was adopted for RC in 2012. In this institution, the service time was not measured as a quality indicator. In the ES, there were records of other indicators, such as number of patients per RC, way of entering the ES, origin, specialty, and care outcomes.

The study population consisted of the medical records of patients treated in the adult ES in 2015. The sample was calculated based on a pilot study to survey the proportions of RC categories, using the simple random sampling technique without replacement, with 95\% confidence, prevalence of $62 \%$ for the green category and maximum admissible error of 2\%, with an estimated minimum number of 2,160 patients. For the selection of participants, considering that the archived medical records were organized by day, month, and year, we opted for systematic sampling, in which a random starting point was drawn and then, in sequence, one in every six individuals in the population was selected to compose the sample, totaling 4,157 medical records of patients 
aged 18 years or older, classified by the MTS from January to December 2015.

Data were accessed at the Medical and Statistical Archiving Service of the institution, through manual consultation of patients' medical records, from September 2015 to February 2016. A form built by the researchers themselves was used, and were analyzed the variables: age, gender, RC category (red, orange, yellow, green, blue, and white); medical specialty of care after RC; time of arrival at ES; RC start and end time; time of start of medical care; and time of discharge, transfer or death. The care outcome variable was categorized into hospital discharge, discharge on request, evasion, dismissed (patients released by the nurse after RC with guidance to seek care in another health unit), transfer, hospitalization, and death.

To calculate the waiting times for care, data were obtained from the date and time of the RC, of nursing and medical records. The variables referring to the service time indicators were measured in minutes, considering: time 1 - time from arrival to the ES until the beginning of the RC; time 2 - duration of the RC; time 3 - time between the end of $R C$ and the beginning of medical care, as determined by the MTS ${ }^{(1,4)}$; time 4 - time from arrival at the ES to the beginning of medical care and time 5 - length of stay in the $E S$, which was measured in hours, from the date and time of the registration of the patient's admission to the $E S$, until the date and the time of hospital discharge, transfer to another service, death or discharge after RC.

Statistical analysis was performed by the Statistical Package for Social Science (SPSS), version 23. Mean, standard deviation, median, 25th and 75th percentiles, minimum and maximum were calculated. For categorical variables, frequency and percentage were calculated.

The difference between the RC end time until the beginning of medical care and the ideal time estimated by the MTS for the red, orange, yellow, green and blue categories was tested using the $t$ test for one sample and were calculated the 95\% confidence intervals. The white color was excluded from this analysis, as there is no indication of time for the beginning of medical care according to the MTS. To associate the average service times with outcomes and the length of stay with RC categories, it was used the analysis of variance (ANOVA). To assess the relationship between service times and RC categories with outcomes, the generalized linear model was used. The significance level considered was 5\% ( $p$ value $<0.05$ )

The study was conducted after approval by the Research Ethics Committee (REC) of the Universidade Federal de São
Paulo, with the consent of the REC of the Universidade Federal do Recôncavo da Bahia, under CAAE: 05739412.9.3003.0056.

\section{RESULTS}

The initial sample consisted of 4,157 medical records of patients treated at the RC, from which 533 who had no record of the RC category were excluded. From the 3,624 medical records analyzed, $51.8 \%$ were female, and the age ranged from 18 to 114 years, with a mean of $48.4 \pm 18.7$ years. Regarding the RC categories, 143 (3.9\%) were classified as red, 769 (21.2\%) as orange, 1,142 (31.5\%) as yellow, 1,004 (27.7\%) as green, 298 (8.2\%) in blue and 268 (7.4\%) in white. As for the referral of patients, from the RC, $59.8 \%$ were directed to care with different medical specialties, $27.8 \%$ to medical clinic, $15.6 \%$ to neurology and $12.3 \%$ to general surgery. Referrals to other medical specialties represented $4.1 \%$, and 40.2\% were dismissed after RC.

Table 1 shows the average waiting service times at the emergency service. It is noteworthy that there was a statistically significant difference in the association between service times and RC categories.

Table 2 shows the difference between the end time of $\mathrm{RC}$ until the beginning of medical care and the ideal time recommended by the MTS.

The results showed that the average waiting time between the end of $\mathrm{RC}$ and the beginning of medical care for patients classified in the red $(p=0.0028)$ and orange $(p<0.0001)$ categories was significantly longer than the recommended ideal. Patients who were classified in the blue and green categories had a significantly shorter time than recommended by the MTS $(p<0.0001)$. For the yellow category, the waiting time was within expected.

There was a statistically significant association between the outcomes of patients classified by the MTS and the different service times in the ES (Table 3).

Patients with the outcome of death had a shorter average waiting time for the beginning of $R C$ and medical care when compared to the others. Patients with hospital discharge had a longer time to start RC than those who were transferred. Those hospitalized had a longer length of stay in the ES; on the other hand, those who were dismissed had a shorter length of stay at the ES and longer waiting time at the RC when compared to the others.

Table 4 shows the relationship between time from arrival to the ES until the beginning of RC and RC categories with outcomes. There was a significant difference for this time in the categories and in the outcomes (Table 4). 
Table 1 - Service times in the emergency service, according to the Manchester Triage System risk classification categories. Salvador, Bahia, Brazil, 2015

\begin{tabular}{|c|c|c|c|c|c|c|}
\hline Service Times & $\mathbf{n}$ & Mean (SD) & $\begin{array}{l}\text { Median } \\
\text { (P25-P75) }\end{array}$ & Minimum & Maximum & p-value \\
\hline Time 1, minute & 3,014 & $33.9(41.8)$ & $21(9-43)$ & 0 & 729 & \\
\hline Time 2, minute & 2,993 & $4.7(3.2)$ & $5(2-5)$ & 3 & 5 & $<0.0001^{\dagger}$ \\
\hline Red & 113 & $2.3(2.6)$ & $2(0-4)$ & 0 & 13 & \\
\hline Orange & 603 & $4.6(2.8)$ & $5(3-5)$ & 0 & 30 & \\
\hline Yellow & 985 & $4.5(2.7)$ & $5(3-5)$ & 0 & 25 & \\
\hline Green & 858 & $4.8(3.4)$ & $5(2-5)$ & 0 & 27 & \\
\hline Blue & 256 & $6.1(4.7)$ & $5(3.5-6)$ & 1 & 30 & \\
\hline White & 178 & $4.5(3.2)$ & $5(2-5)$ & 1 & 20 & \\
\hline Time 3, minute & 579 & $45.2(58.9)$ & $29(5-60)$ & 0 & 375 & $<0.0001^{+}$ \\
\hline Red & 75 & $3.0(8.3)$ & $0(0-2)$ & 0 & 53 & \\
\hline Orange & 151 & 39.5 (55.8) & $15(5-54)$ & 0 & 320 & \\
\hline Yellow & 236 & $54.8(61.4)$ & $35(18.5-65)$ & 0 & 361 & \\
\hline Green & 84 & $60.6(56.5)$ & $47.6(25-85)$ & 0 & 325 & \\
\hline Blue & 15 & $72.5(66.4)$ & $50(21-105)$ & 0 & 206 & \\
\hline White & 18 & $49.6(86.5)$ & $23(9-61)$ & 2 & 375 & \\
\hline Time 4, minute & 646 & $72.4(67.4)$ & $54(23-103)$ & 0 & 419 & $<0.0001^{\dagger}$ \\
\hline Red & 93 & $8.6(14.6)$ & $3(0-12)$ & 0 & 79 & \\
\hline Orange & 173 & $69.9(62.9)$ & $50(26-102)$ & 5 & 328 & \\
\hline Yellow & 251 & $88.0(66.7)$ & $69(43-109)$ & 4 & 387 & \\
\hline Green & 89 & $98.2(66.2)$ & $86(52-127)$ & 13 & 419 & \\
\hline Blue & 16 & $101.9(66.1)$ & $86.5(47.5-145)$ & 17 & 228 & \\
\hline White & 24 & $59.2(79.1)$ & $42(14-76)$ & 0 & 385 & \\
\hline
\end{tabular}


Table 1 - Cont.

\begin{tabular}{lccccc} 
Service Times & $\mathbf{n}$ & Mean (SD) & $\begin{array}{c}\text { Median } \\
\text { (P25-P75) }\end{array}$ & Minimum & Maximum \\
$\begin{array}{lcccc}\text { Time 5, hours* } \\
\text { Red }\end{array}$ & 2,298 & $3.8(7.9)$ & $1.2(0.4-3.9)$ & 0 & 168.8 \\
Orange & 114 & $5.1(7.3)$ & $1.5(0.3-7.2)$ & 0 & 34 \\
Yellow & 384 & $9.2(14.8)$ & $5.3(2.3-10.3)$ & 0.05 & 168.8 \\
Green & 698 & $3.7(5.7)$ & $1.6(0.5-4.6)$ & 0.03 & 27.1 \\
Blue & 777 & $1.5(2.6)$ & $0.6(0.3-1.4)$ & 0.03 & 29.7 \\
White & 242 & $1.2(2.6)$ & $0.7(0.4-1.2)$ & 0.05 & 56.2 \\
\hline
\end{tabular}

SD: standard deviation; P25-75: Interquartile range 25-75; Time 1: arrival at ES until beginning of RC; Time 2: duration of RC; Time 3: end of RC and start of medical care; Time 4: arrival at the ES until the beginning of medical care; Time 5: stay in ES;" Losses in the sample of valid medical records (absence of record); ${ }^{\dagger}$ Analysis of variance.

Table 2 - Time between the end of risk classification and the beginning of medical care (minutes), by risk classification category, compared to that recommended by the Manchester Triage System. Salvador, Bahia, Brazil, 2015

\begin{tabular}{|c|c|c|c|c|c|}
\hline RC categories & $\mathbf{n}^{*}$ & Mean (SD) & $95 \% \mathrm{Cl}$ & Ideal time & p-value ${ }^{t}$ \\
\hline Red & 75 & $3(8.3)$ & $1.1-4.8$ & 0 & 0.0028 \\
\hline Orange & 151 & $39.5(55.8)$ & $30.6-48.4$ & 10 & $<0.0001$ \\
\hline Yellow & 236 & $54.8(61.4)$ & $47-62.6$ & 60 & 0.1945 \\
\hline Green & 84 & $60.6(56.5)$ & $48.5-72.7$ & 120 & $<0.0001$ \\
\hline Blue & 15 & 72.5 (66.4) & $38.9-106.1$ & 240 & $<0.0001$ \\
\hline
\end{tabular}

RC: risk classification; SD: standard deviation; $95 \% \mathrm{Cl}$ : $95 \%$ confidence interval; $\mathrm{n}$ : absolute number; 'Losses in the sample of valid medical records (absence of record and exclusion of the white category); ${ }^{\dagger} t$ test for one sample.

For patients in the red and white categories, those with the outcome of death had shorter waiting times from arrival to the ES until the beginning of RC compared to the others $(p=0.000)$. For patients in the orange, yellow, green, and blue categories, those who were dismissed had a longer waiting time for the beginning of RC compared to those with hospital discharge $(p=0.000)$.

The relationship between the length of stay in the ES and the RC categories with the outcome was also statistically significant (Table 5). 
Table 3 - Service times in the emergency service, according to patient outcomes classified by the Manchester Triage System. Salvador, Bahia, Brazil, 2015

\begin{tabular}{|c|c|c|c|c|c|c|c|}
\hline \multirow{2}{*}{$\begin{array}{l}\text { Average } \\
\text { of service } \\
\text { times }\end{array}$} & \multicolumn{6}{|c|}{ Outcomes } & \multirow[b]{2}{*}{ p-value } \\
\hline & $\begin{array}{l}\text { Hospital } \\
\text { discharge } \\
(n=1554)\end{array}$ & $\begin{array}{c}\text { Discharge } \\
\text { on request } \\
\text { or evasion } \\
\text { ( } n=163)\end{array}$ & $\begin{array}{c}\text { Dismissed } \\
(n=1454)\end{array}$ & $\begin{array}{l}\text { Hospitalization } \\
\qquad(\mathrm{n}=\mathbf{8 3})\end{array}$ & $\begin{array}{l}\text { Transfer } \\
(n=275)\end{array}$ & $\begin{array}{l}\text { Death } \\
(n=95)\end{array}$ & \\
\hline \multirow{2}{*}{$\begin{array}{l}\text { Time } \\
1, \text { minutes* }\end{array}$} & $n=1,277$ & $n=134$ & $n=1,251$ & $n=62$ & $n=202$ & $n=88$ & \\
\hline & $31.9(42.2)$ & $26.1(32.3)$ & $41.4(44.5)$ & $29.5(38.8)$ & $18.9(20.7)$ & 8.8 (19.6) & $0.0001^{+}$ \\
\hline \multirow{2}{*}{$\begin{array}{l}\text { Time } \\
2, \text { minutes }\end{array}$} & $n=1,268$ & $n=134$ & $n=1,250$ & $n=62$ & $n=200$ & $n=79$ & \\
\hline & $4.5(2.3)$ & $4.3(1.9)$ & $5.1(3.8)$ & $4.7(1.9)$ & $4.9(3.4)$ & $1.8(2.5)$ & $0.0001^{+}$ \\
\hline \multirow{2}{*}{$\begin{array}{l}\text { Time } \\
3, \text { minutes }^{*}\end{array}$} & $n=428$ & $n=41$ & $n=0$ & $n=10$ & $n=41$ & $n=59$ & \\
\hline & $49.9(61.4)$ & $61.4(63.5)$ & - & $54.5(64.6)$ & 36.6 (38.3) & $4.3(13.8)$ & $0.0001^{\dagger}$ \\
\hline \multirow{2}{*}{$\begin{array}{l}\text { Time } \\
4 \text {, minutes* }\end{array}$} & $n=475$ & $n=46$ & $n=0$ & $n=10$ & $n=47$ & $n=68$ & \\
\hline & $81.4(67)$ & $87.4(76.7)$ & - & $76.6(66.4)$ & $58.6(46.2)$ & $8.9(19.9)$ & $0.0001^{+}$ \\
\hline \multirow{2}{*}{$\begin{array}{l}\text { Time } \\
5, \text { hours }^{*}\end{array}$} & $n=777$ & $n=84$ & $n=1,246$ & $n=18$ & $n=81$ & $n=92$ & \\
\hline & $7(7.5)$ & $6.4(6.3)$ & $0.8(0.8)$ & $42(45.3)$ & $4.9(6.9)$ & $5.5(11.4)$ & $0.0001^{+}$ \\
\hline
\end{tabular}

Times expressed as mean (standard deviation); n: absolute number; Time 1: arrival at ES until beginning of RC; Time 2: duration of RC; Time 3: end of RC and beginning of medical care; Time 4: arrival at the ES until the beginning of medical care; Time 5: stay in ES; "Losses in the sample of valid medical records (absence of record); † Analysis of variance.

In the red category, patients with the outcome of death had a shorter average length of stay in the ES when compared to the others; in the orange category, those with hospitalization outcome had a longer length of stay than the others; in the yellow category, those with the outcome of death had a longer stay than the others. For the orange, yellow, green, blue, and white categories, patients dismissed after RC had a shorter length of stay in the ES than the others. For the white category, patients with the outcome of death had a longer length of stay than those with other outcomes.

\section{DISCUSSION}

The demand that is not relevant to the emergency hospital service, that is, users without urgent health needs, made necessary to implement the RC, using protocols, including the
MTS, whose main objective is to optimize the waiting time for the first medical evaluation, through the prioritization of acute cases that threaten life. Thus, knowing the adequacy of the service time to the recommended is essential for achieving this goal and for patient safety, as the increase in waiting time can cause the death of a patient with severe acute clinical conditions. In this research, it was also evaluated the relationship between service times, RC categories and outcomes, in order to contribute to the organization of flows and management of the ES.

The most frequent clinical priority was the yellow classification (31.5\%), followed by green (27.7\%). This result was similar to that of other investigations developed in public hospitals in Minas Gerais ${ }^{(6-7,12)}$, a pioneering state in the implementation of the MTS in Brazil. These findings indicate that the search for care for low-priority clinical demands in ES is still the option of SUS users. 
Table 4 - Average waiting time between arrival at the emergency service until the beginning of risk classification and risk classification categories, by outcome of patients classified by the Manchester Triage System. Salvador, Bahia, Brazil, 2015

\begin{tabular}{|c|c|c|c|c|c|c|}
\hline \multirow{2}{*}{$\begin{array}{l}\text { Average time from } \\
\text { arrival at ES to } \\
\text { beginning of } R C \text {, } \\
\text { minute * }\end{array}$} & \multicolumn{6}{|c|}{ Outcomes } \\
\hline & $\begin{array}{l}\text { Hospital } \\
\text { discharge } \\
(n=1,277)\end{array}$ & $\begin{array}{l}\text { Discharge } \\
\text { on request } \\
\text { or evasion } \\
(n=134)\end{array}$ & $\begin{array}{l}\text { Dismissed } \\
(n=1,251)\end{array}$ & $\begin{array}{l}\text { Hospitalization } \\
\qquad(n=62)\end{array}$ & $\begin{array}{l}\text { Transfer } \\
(n=202)\end{array}$ & $\begin{array}{l}\text { Death } \\
(n=88)\end{array}$ \\
\hline \multirow[t]{2}{*}{ Red } & $n=45$ & $n=2$ & $n=0$ & $n=4$ & $n=6$ & $n=68$ \\
\hline & $13.2(16.4)$ & $34.5(31.8)$ & - & $7.7(7.5)$ & $6(7.7)$ & $5.5(18)$ \\
\hline \multirow[t]{2}{*}{ Orange } & $n=443$ & $n=54$ & $n=28$ & $n=35$ & $n=34$ & $n=15$ \\
\hline & $33.2(42.5)$ & $21.5(29.8)$ & $46.1(50)$ & $26(28.3)$ & $18.8(16.7)$ & $22.5(22.9)$ \\
\hline \multirow[t]{2}{*}{ Yellow } & $\mathrm{n}=522$ & $n=56$ & $n=354$ & $n=16$ & $n=37$ & $n=2$ \\
\hline & $33.4(36.4)$ & $27.2(36.3)$ & $43(50.2)$ & $44.5(60.9)$ & $26.5(32.8)$ & $17.5(7.8)$ \\
\hline \multirow[t]{2}{*}{ Green } & $n=187$ & $\mathrm{n}=17$ & $n=644$ & $n=1$ & $\mathrm{n}=9$ & $\mathrm{n}=0$ \\
\hline & $30.4(34.5)$ & $36(30.6)$ & $40(43.1)$ & $53(-)$ & $32(15)$ & - \\
\hline \multirow[t]{2}{*}{ Blue } & $n=29$ & $n=3$ & $n=218$ & $n=0$ & $n=6$ & $\mathrm{n}=0$ \\
\hline & $21.8(18.4)$ & $20.3(11.9)$ & $41.4(36.0)$ & - & $19.5(15.7)$ & - \\
\hline \multirow[t]{2}{*}{ White } & $n=51$ & $n=2$ & $n=7$ & $n=6$ & $n=110$ & $\mathrm{n}=3$ \\
\hline & $31.5(101.7)$ & $36(8.5)$ & $67.6(72.3)$ & $20.5(19.7)$ & $15.9(16.2)$ & $10.7(16.7)$ \\
\hline $\mathrm{p}$-value $(\mathrm{RC})$ & $0.0000^{+}$ & & & & & \\
\hline $\mathrm{p}$ - value (time) & $0.0000^{\dagger}$ & & & & & \\
\hline $\mathrm{p}$ - value ( $\mathrm{RC}$ versus time) & $0.0000^{\dagger}$ & & & & & \\
\hline
\end{tabular}

ES: emergency service; RC: risk classification; Times expressed as mean (standard deviation); $n$ : absolute number; "Losses in the sample of valid medical records (absence of record); ‘Generalized linear model.

On the other hand, there is a low frequency of patients classified as red (3.9\%), which can be attributed to the dynamics of the ES, in which patients admitted in life-threatening situations are not classified, as they are referred for care immediately - a reality similar to that described in other studies $^{(6,10)}$. In these cases, it is recommended to record the $\mathrm{RC}$ retrospectively ${ }^{(10)}$.

Among patients referred for medical care after RC, most had their first assessment with a clinical physician, which is similar to other researches ${ }^{(10,15)}$ that identified MTS more associated with admission for care by clinical than surgical specialties. Another fact that can contribute to understanding this demand is the growth of the elderly population, in which there is a prevalence and increase of chronic diseases ${ }^{(15)}$.

In this research, the average waiting service times were verified as indicators of quality of care in the RC. The average time from arrival at the ES to the beginning of RC was 33.9 minutes, with a median of 21 minutes. It is believed that the excessive waiting time for the $\mathrm{RC}$ was related to the increase in demand, which often exceeds its service capacity. Research carried out in other Brazilian ${ }^{(6-7,10)}$ and European ${ }^{(13)}$ institutions identified lower times, with medians between 6 and 7 minutes, corroborating the MTS recommendation of not exceeding 10 minutes $^{(1,4)}$. 
Table 5 - Length of stay in the emergency service and risk classification categories, by outcome of patients classified by the Manchester Triage System. Salvador, Bahia, Brazil, 2015

\begin{tabular}{|c|c|c|c|c|c|c|}
\hline \multirow{2}{*}{$\begin{array}{l}\text { Length of } \\
\text { stay in the } \\
\text { ES (hours) }\end{array}$} & \multicolumn{6}{|c|}{ Outcome } \\
\hline & $\begin{array}{l}\text { Hospital } \\
\text { discharge } \\
(n=777)\end{array}$ & $\begin{array}{l}\text { Discharge on } \\
\text { request or evasion } \\
(n=84)\end{array}$ & $\begin{array}{l}\text { Dismissed } \\
(n=1,246)\end{array}$ & $\begin{array}{l}\text { Hospitalization } \\
\qquad(\mathrm{n}=18)\end{array}$ & $\begin{array}{l}\text { Transfer } \\
(\mathbf{n}=\mathbf{8 1})\end{array}$ & $\begin{array}{l}\text { Death } \\
(n=92)\end{array}$ \\
\hline \multirow[t]{2}{*}{ Red } & $n=38$ & $n=2$ & - & $n=2$ & $n=4$ & $n=68$ \\
\hline & $7.9(7.1)$ & $22.1(16.9)$ & - & $7.2(8.4)$ & $15.4(10.3)$ & $2.3(4.9)$ \\
\hline \multirow[t]{2}{*}{ Orange } & $n=277$ & $n=36$ & $n=28$ & $n=13$ & $n=13$ & $n=17$ \\
\hline & $8.5(9.5)$ & $6.5(6.7)$ & $1.5(1.9)$ & $48.7(49.9)$ & $6.7(8.8)$ & $10.6(15.8)$ \\
\hline \multirow[t]{2}{*}{ Yellow } & $n=293$ & $n=35$ & $n=350$ & $n=1$ & $n=16$ & $n=3$ \\
\hline & $6.4(5.9)$ & $5.9(4.3)$ & $0.8(0.8)$ & $71.2(-)$ & $3.4(3.1)$ & $21.3(15.1)$ \\
\hline \multirow[t]{2}{*}{ Green } & $n=121$ & $n=8$ & $n=644$ & - & $n=4$ & - \\
\hline & $5.1(4.8)$ & $5.6(5.8)$ & $0.7(0.7)$ & - & $3.6(4.4)$ & - \\
\hline \multirow[t]{2}{*}{ Blue } & $n=18$ & - & $n=218$ & - & $n=6$ & - \\
\hline & $4.1(4.7)$ & - & $0.8(0.6)$ & - & $8.5(11.5)$ & - \\
\hline \multirow[t]{2}{*}{ White } & $n=30$ & $n=3$ & $n=6$ & $n=2$ & $n=38$ & $n=4$ \\
\hline & $7.4(8.1)$ & $3.8(2.7)$ & $1.4(1.2)$ & $18.9(0.2)$ & $3.3(5.1)$ & $27.4(24.7)$ \\
\hline $\begin{array}{l}p \text {-value (RC) } \\
p \text {-value (time) } \\
p \text {-value (RC ve }\end{array}$ & $\begin{aligned} & < \\
& < \\
\text { Is time) } & <\end{aligned}$ & $\begin{array}{l}001^{+} \\
001^{\dagger} \\
001^{\dagger}\end{array}$ & & & & \\
\hline
\end{tabular}

ES: emergency service; RC: risk classification; Times expressed as mean (standard deviation); $n$ : absolute number; "Losses in the sample of valid medical records (absence of record); †Generalized linear model.

As for the average duration of the $\mathrm{RC}$ spent by the nurse in prioritizing the patient, the median found for the orange, yellow, green, blue and white categories was 5 minutes, which demonstrates a high time. MTS recommends optimal time for the RC event of a maximum of 3 minutes - estimated time for fast and accurate prioritization ${ }^{(1)}$. The red category differed from the others, with a median of 2 minutes, a finding that is similar to other investigations ${ }^{(6-7,10)}$. This is because the beginning of the first medical evaluation should not be a reason for delay ${ }^{(1,4)}$.

Using tools such as the multiparameter monitor to quickly identify the patient's status and computerize the RC protocol can facilitate data collection, reduce RC time, and improve the accuracy of recording all service times. A recent study found that recording in electronic medical records had higher reliability and accuracy for the variable "vital signs", and the time spent with RC was significantly less when compared to the use of manual records ${ }^{(16)}$.

A finding that drew attention was the number of patients without record of the time between the end of RC and the beginning of medical care. This loss was attributed to the lack of description of the start time of medical care and, to a lesser extent, the end time of the RC. This waiting time is an important indicator established by the MTS and must be measured to assess whether medical care occurs as recommended by the patient's clinical severity ${ }^{(1)}$. A study 
with similar characteristics also showed losses in the sample of valid medical records $s^{(6)}$.

A significant difference was found between the time from the end of the RC to the beginning of medical care by $\mathrm{RC}$ category and the times recommended by the MTS. The average waiting times for patients with red and orange priorities were significantly longer than the maximum response times estimated by the MTS - results similar to those of other national surveys ${ }^{(6-7)}$. These findings reinforce the need to establish health care flows, to minimize waiting times and adapt them to what is recommended by the protocol ${ }^{(7)}$, especially with regard to the high severity categories, in which there is a greater risk of clinical deterioration.

On the other hand, the average time between the end of $R C$ and the beginning of medical care, for patients classified in the red category, was 3 minutes. This result may be overestimated, since, to ensure immediate care for emerging patients, the opening of the care form at the reception is performed after the service, in the red room.

Regarding the time between arrival at the ES until the beginning of medical care, in general, patients waited, on average, 72.4 minutes. This time is directly influenced by the estimated time between the patient's arrival at the ES and the performance of the RC. Although the MTS does not describe this indicator, the measure was used by another Brazilian study, which showed an average of 52 minutes ${ }^{(7)}$, that is, lower than that found in this research. The delay for medical care in the ES goes beyond the prioritization performed by the RC nurse ${ }^{(4)}$, and it is necessary to include it in the assessment of the service, as the patient may clinically deteriorate before the RC.

Thus, long waiting times are associated with unfavorable results in the treatment and clinical evolution of the patient, greater suffering for those who wait and dissatisfaction with the care provided in the ES, in addition to favoring the configuration of stressful environments, both for the care team and the users ${ }^{(8)}$. On the other hand, the dimensioning of professionals working in the ES and the insufficient number of $\mathrm{RC}$ rooms operated by nurses to immediately meet the demand of patients who arrive at the ES can also make care slow down ${ }^{(7-8)}$.

The average length of stay in the $\mathrm{ES}$, despite the $\mathrm{RC}$, was less than 24 hours. This trend was found in other national researches ${ }^{(11-12)}$, which can be explained by the fact that most patients are discharged after medical care or have been dismissed after RC.

Regarding the length of stay related to RC, patients in the orange category (very urgent) had a longer length of stay, with a maximum duration of 168.8 hours. This can be explained by several factors: need for further diagnostic investigations, severity of the patient with comorbid conditions, availability of hospital beds and waiting time for specialist consultations ${ }^{(5,12)}$.

In the analysis of the average service time with outcomes, it was found that patients with the outcome of death had shorter time from arrival to the ES to the beginning of the $R C$ and length of stay in the ES, which suggests the appropriate use of the MTS protocol as a demand organizer, prioritizing more severe patients ${ }^{(10)}$. In another study, the MTS proved to be a good predictor for length of hospital stay and death outcome ${ }^{(11)}$.

In this study, patients who were dismissed had a longer average waiting time from arrival to the ES until the beginning of the RC, in addition to a shorter length of stay in the ES. In the hospital where the study was carried out, low complexity users continue to use the ES as the main gateway to the health system and, in most cases, are released after the RC with guidance to look for another service. In this hypothesis, it is essential to build clear flows previously agreed upon within the Emergency Care Network ${ }^{(1,3)}$, in order to support the role of nurses in the RC.

Different strategies have been proposed to optimize the care flow and reduce patient waiting times at the ES. A research found that the addition of a flow coordinator physician in the triage significantly increased the proportion of patients who had their first medical evaluation within the established deadlines ${ }^{(5)}$. Furthermore, the implementation of a fast track way reduced the proportion of patients who left without being seen by the physician, consolidating the role of the ES to compensate for deficiencies in access to Primary Care ${ }^{(14)}$. However, these strategies did not bring significant benefits to reduce the length of stay in the $\mathrm{ES}^{(5,14)}$.

On the other hand, new strategies that enable more autonomy for nurses in the $\mathrm{RC}$, reduce waiting times, stay in the ES, and contribute to improving patient satisfaction, need to be discussed in the national context. A review carried out on the RC nurse's attributions indicated that, in other countries, nurses are authorized to initiate therapeutic procedures, prescribe the administration of oral and inhaled medications and even perform electrocardiogram, laboratory and radiological exams, when necessary ${ }^{(17)}$, which can help physicians to decide more quickly about treatment.

When analyzing the relationship between length of stay and RC category with outcomes, it was observed that patients in the red category who died had a shorter average length of stay (2.3 hours), which may be related to the admission of patients to the red room at imminent risk of death, such as gunshot wounds and cardiopulmonary arrest, which often do not resist cardiopulmonary resuscitation maneuvers, evolving to death. 
Other evidence has already demonstrated a clear association between the MTS priority group and outcomes ${ }^{(11-12)}$. The MTS was also described as a good indicator to differentiate patients at risk of death, as well as those who remain in the hospital for at least 24 hours and those who are discharged ${ }^{(12)}$.

Also regarding the length of stay in the ES, patients classified in the yellow, green and blue categories who were dismissed had an average length of stay of less than 1 hour. All patients who seek the ES must be classified and have the right to wait for medical care or may be referred to other services through previously agreed flows ${ }^{(1,3)}$. The demand that is not relevant to the hospital emergency service has important implications for the response time and can lead to delays in the care of situations that really put the patient's life at risk.

In the orange category, patients with hospitalization outcome had a longer average length of stay in the ES (47.8 hours). Corroborating the findings of this study, a national research found that orange patients had 32 times greater risk of being hospitalized compared to a lower priority group ${ }^{(12)}$.

Despite advances in the use of the MTS in clinical risk management, there are still gaps in the management of Brazilian public ES, due to their overcrowding. In an attempt to change this reality, improve the flow of patients and reduce the length of stay, strategies have been used for bed management, such as the Kanban, a tool that visually signals the time that the patient remains in the ES receiving care and, consequently, occupying a bed. Kanban has been an increasingly used strategy to face overcrowding in the ES ${ }^{(18)}$ and was used at the time of the research in the hospital studied. Through this strategy, teams monitor and diagnose the causes of increased length of stay and solve them.

Another strategy that has been applied to ES who suffer from the chronic situation of overcrowding is the approach called Lean, which consists of a management philosophy applied to improve time-based processes, in addition to aiming at changing hospital cultures ${ }^{(19)}$. Studies carried out in ES in several European countries ${ }^{(14)}$ demonstrated that the main impacts arising from the application of Lean were reduced waste (long waiting periods) and improved patient flow, bed turnover and quality of care. However, a literature review shows that the experience with the application of Lean in Brazilian ES is incipient ${ }^{(20)}$.
Finally, the MTS was designed to prioritize patients in the ES, but it is undoubtedly a useful tool to assist in hospital management during the process of assessing the quality of care in the $\mathrm{ES}^{(12)}$ and in measuring the times involved in the process of $\mathrm{RC}$ care, a stage for which the nurse has full responsibility ${ }^{(10)}$.

\section{CONCLUSION}

It is high the demand for medium and low complexity care in the emergency service, with an average waiting time for the beginning and duration of the risk classification greater than that recommended by the MTS.

There was a difference between the average time between the end of the risk classification and the beginning of medical care and that recommended in the priority categories of the MTS. Patients in the orange and red category had a longer average waiting time, which suggests the need to continuously monitor the system. However, the average waiting time for the green and blue categories was less than the estimated maximum, and for the yellow category the time was within expectation. Shorter waiting times for the beginning of $\mathrm{RC}$ and shorter periods of stay in the ES were related to the red category and the death outcome.

The use of the MTS was fundamental for the prioritization of severe cases, however, it is necessary to implement strategies that reorganize the care flow of the risk classification, with a view to reducing waiting times for care, especially in the high-priority categories, in addition to ensuring responsible referral for less urgent demand.

This study had as a limitation the incompleteness of the records, which is a weakness of retrospective studies, the manual recording of times and the fact that it was carried out in a single center. However, it is noteworthy that it was the first developed in this region of Brazil to evaluate the service time as an indicator of the quality of the risk classification.

This investigation produced important data, which should contribute to expanding the production of knowledge about risk classification indicators and performance evaluation of protocols in emergency services, increasing patient safety in these units. Based on these results, nurses and managers can build quality indicators to assess risk classification and, thus, organize the care flow to improve patient care in the emergency service. 


\section{REFERENCES}

1. Grupo Brasileiro de Classificação de Risco. Diretrizes para implementação do Sistema Manchester de Classificação de Risco nos pontos de atenção às urgências e emergências [Internet]. Belo Horizonte: GBCR; 2017 [cited 2020 Apr 10]. Available from: https:/www.gbcr.org.br/wp-content/uploads/2021/03/DIRETRIZES.pdf

2. Chiu IM, Lin YR, Syue YJ, Kung CT, Wu KH, LiCJ. The influence of crowding on clinical practice in the emergency department. Am J Emerg Med. 2018;36(1):56-60. doi: https://doi.org/10.1016/j.ajem.2017.07.011

3. Souza TH, Andrade SR. Embracement with risk classification: an indicator of the emergency demand on a hospital service. Cogitare Enferm. 2014;19(4):643-50. doi: http://doi.org/10.5380/ce.v19i4.35941

4. Mackway-Jones K, Marsden J, Windle J, editors. Emergency triage. 3rd ed. Cowley, Oxford: BMJ Books; 2014 [cited 2020 Apr 11]. Available from: https:// books.google.com.br/books?hl=ptBR\&lr=\&id=KQRfAQAAQBAJ\&oi=fnd\&p $g=$ PR6\&ots=4YN5ZHIz75\&sig=Gn7vTFAx_GSoyAmoSQ_LphaFv40\&redir_esC $=\mathrm{y} \# \mathrm{v}=$ onepage $\& \mathrm{q} \& \mathrm{f}=\mathrm{false}$

5. Oliveira MM, Marti C, Ramlawi M, Sarasin FP, Grosgurin O, Poletti PA, et al. Impact of a patient-flow physician coordinator on waiting times and length of stay in an emergency department: a before-after cohort study. PLOS One. 2018;13(12):e0209035. doi: https://doi.org/10.1371/journal.pone.0209035

6. Silva ADC, ChiancaTCM, Pádua DR, Guimarães GL, Manzo BF, Correa AR. Characteristics of care of a public emergency room according to the manchester triage system. Rev Min Enferm. 2019;23:e-1178. doi:https://doi.org/10.5935/1415-2762.20190026

7. Chianca TCM, Costa RM, Vidigal MV, Silva LCR, Diniz GA, Araújo JHV, et al. Waiting time for assistance using the machester triage system in an emergency hospital. Rev Min Enferm. 2016;20:e988. doi: https://doi.org/10.5935/1415-2762.20160058

8. Hermida PMV, Nascimento ERP, Echevarría-Guanilo ME, Vituri DW, Martins SR, Barbosa SS. Responsivenes of the embracement with risk cassification: user's evaluation in emergency care unit. Texto Contexto - Enferm. 2019;28:e20180480. doi: http://doi.org/10.1590/1980-265x-tce-2017-0480

9. Báo ACP, Amestoy SC, Moura GMSS, Trindade LL. Quality indicators: tools for the management of best practices in health. Rev Bras Enferm. 2019;72(2):360-6. doi: http://doi.org/10.1590/0034-7167-2018-0479

10. Anziliero F, Soler BED, Silva BA, Tanccini T, Beghetto MG. Manchester system: time spent on risk classification and priority of care at an emergency medical service. Rev Gaúcha Enferm. 2016;37(4):e64753. doi: https://doi. org/10.1590/1983-1447.2016.04.64753
11. Guedes HM, Araújo FA, Pinto Júnior D, Martins JCA, Chianca TCM. Outcome assessment of patients classified through the manchester triage system in emergency units in Brazil and Portugal. Invest Educ Enferm. 2017;35(2):174-81. doi: https://doi.org/10.17533/udea.iee.v35n2a06

12. Gonçales PC, Pinto Júnior D, Salgado PO, Chianca TCM. Relationship between risk stratification, mortality and length of stay in a emergency hospital. Invest Educ Enferm. 2015;33(3):424-31. doi: https://doi.org/10.17533/udea.iee.v33n3a05

13. Storm-Versloot MN, Vermeulen H, van Lammeren N, Luitse JSK, Goslings JC. Influence of the manchester triage system on waiting time, treatment time, length of stay and patient satisfaction; a before and after study. Emerg Med J. 2014;31(1):13-8. doi: http://doi.org/10.1136/emermed-2012-201099

14. Chrusciel J, Fontaine X, Devillard A, Cordonnier A, Kanagaratnam L, Laplanche $D$, et al. Impact of the implementation of a fast-track on emergency department length of stay and quality of care indicators in the Champagne-Ardenne region: a before-after study. BMJ Open. 2019;9(6):e026200. doi: https://doi.org/10.1136/ bmjopen-2018-026200

15. Brouns SHA, Mignot-Evers L, Derkx F, Lambooij SL, Dieleman JP, Haak HR. Performance of the manchester triage system in older emergency department patients: a retrospective cohort study. BMC Emerg Med. 2019;19:3. doi: https:// doi.org/10.1186/s12873-018-0217-y

16. Cicolo EA, Peres HHC. Electronic and manual registration of manchester system: reliability, accuracy, and time evaluation. Rev Latino-Am Enferm. 2019;27:e3241. doi: https://doi.org/10.1590/1518-8345.3170.3241

17. Acosta AM, Duro CLM, Lima MADS. Activities of the nurse involved in triage/ risk classification assessment in emergency services: an integrative review. Rev Gaúcha Enferm. 2012;33(4):181-90. doi: https://doi.org/10.1590/ S1983-14472012000400023

18. Cecílio LCO, Reis AAC, Andreazza R, Spedo SM, Cruz NLM, Barros LS, et al. Nurses in the Kanban: are there news meanings of professional practice in innovative tools for hospital care management? Ciênc Saúde Coletiva. 2020;25(1):283-92. doi: https://doi.org/10.1590/1413-81232020251.28362019

19. Improta G, Romano M, Di Cicco MV, FerraroA, Borrelli A, Verdoliva C, et al. Lean thinking to improve emergency department throughput at AORN Cardarelli hospital. BMC Health Serv Res. 2018;18(1):914. doi: https://doi.org/10.1186/ s12913-018-3654-0

20. Magalhães ALP, Erdmann AL, Silva EL, Santos JLG. Lean thinking in health and nursing: an integrative literature review. Rev Latino-Am Enfermagem. 2016;24:e2734. doi: http://doi.org/10.1590/1518-8345.0979.2734 
Jesus APS, Batista REA, Campanharo CRV, Lopes MCBT, Okuno MFP

\section{- Acknowledgments:}

Coordination for the Improvement of Higher Education Personnel (Coordenação de Aperfeiçoamento de Pessoal de Nível Superior - CAPES).

\section{- Authorship contribution:}

Conceptualization: Ana Paula Santos de Jesus, Ruth Ester Assayag Batista, Meiry Fernanda Pinto Okuno, Cassia Regina Vancini Campanharo, Maria Carolina Barbosa Teixeira Lopes, Meiry Fernanda Pinto Okuno. Data curation: Ana Paula Santos de Jesus.

Formal analysis: Ana Paula Santos de Jesus.

Funding acquisition: Ana Paula Santos de Jesus, Ruth Ester Assayag Batista

Investigation: Ana Paula Santos de Jesus.

Methodology: Ana Paula Santos de Jesus, Ruth Ester Assayag Batista, Meiry Fernanda Pinto Okuno, Cassia Regina Vancini Campanharo, Maria Carolina Barbosa Teixeira Lopes.

Writing-original draft: Ana Paula Santos de Jesus, Ruth Ester Assayag Batista.

Writing-review \& editing: Ana Paula Santos de Jesus, Ruth Ester Assayag Batista, Cassia Regina Vancini Campanharo, Maria Carolina Barbosa Teixeira Lopes, Meiry Fernanda Pinto Okuno.

The authors declare that there is no conflict of interest.

\section{- Corresponding author:}

Ana Paula Santos de Jesus

E-mail: ana_paula@ufrb.edu.br

\section{Associate editor:}

Graziella Badin Alit 